\title{
MAEU UAV System for Topographic Survey of Transmission Line In Myanmar
}

\author{
Mr. Aung Lwin Moe \\ Department of UAV Research \\ Myanmar Aerospace Engineering University \\ Meiktila, Myanmar
}

\author{
Mr. Thet Naing Soe \\ Department of UAV Research \\ Myanmar Aerospace Engineering University \\ Meiktila, Myanmar
}

\author{
Prof. Dr. Khaing Khaing Soe \\ Department of UAV Research \\ Myanmar Aerospace Engineering University \\ Meiktila, Myanmar
}

\begin{abstract}
The use of Unmanned Aerial Vehicles (UAVs) for surveying is now widespread and operational for several applications- archeological site surveys, forest management, aerial mapping for smart city, land monitoring and others. In engineering survey works, the conventional survey involves huge cost, labour, and time. UAVs are very practical in providing reliable information and can provide the output that meets the accuracy of engineering surveys. This paper aims to show the potential of using MAEU UAV for topographic survey of transmission line. To accomplish this, the system was designed to incorporate light weight, endurance covered 1 hour, payload $2 \mathrm{~kg}$, equipped with specialized design to get the safety conditions in Pegu mountainous region. The research process included an optimization of airframe design, flight stability and performance, and flight process for topographic survey.
\end{abstract}

Keywords-Unmanned Aerial Vehicle; Aircraft design and structure; Autonomous flight reliability; Aerial survey planning; Ground control system.

\section{INTRODUCTION}

The development of UAVs has become an active area of research nowadays and very interesting devices have been developed and deployed. This paper is based on the practical approaches which were developed in department of UAV research at Myanmar Aerospace Engineering University. In 2007, UAV research was initiated to gain the strong technology. The department of UAV research have been playing important role in aeronautical field in Myanmar since 2010. As a research for economics, this department was able to operate aerial photographing for civilian applications.

In the developing countries, two aspects that limit the adoption of UAV technology for research purposes are the hight cost and optimized design philosophy. The paper attempts to solve these problems by presenting airframe design that is focused on low cost while maintaining a resonable level fo performance. The designs and structures of MAEU UAV was considered according to the properties of Balsa wood, high strength and light weight and built by using calculated design results. Some minor preparations were made by using trial- and-error method to improve the performance of the UAV. The lack of test instruments lead to use trial-anderror method.
The development of the UAVs in Myanmar Aerospace Enginnering University has the following mission:

- Develop know-how of UAV for several applications

- Provide experimental platform and tool for multiresearch related to UAV applications

- Applying civilian applications by using aerospace technology

- Upgrade research developing economy

For aerial survey applications, the payload of the whole system is composed of a camera, Global Navigation Satellite System (GNSS) and inertial measurement unit. The camera takes overlapping images as it flies over the instresting area An onboard GNSS device allows these data products to be georeferenced. However, in low cost UAVs, the accuracy of such GNSS is often limited. Therefore, supplementary ground control points (GCPs) are usually acquired in order to maintain the accuracy of the image block orientation and derived mapping products.

\section{MAEU UAV SYSTEM DESIGN AND DEVELOPMENT}

\section{A. Design Methodology}

The mission requirements of the MAEU UAV to use in mountainous area are

- Range - 25-50 km operate

- Endurance - about $1 \mathrm{hr}$

- Payload - $2 \mathrm{~kg}$

- Capable of fully autonomous flying.

The MAEU UAV should satisfy (1) able to accommodate for equipment related to research and development work, (2) safe to operate, (3) reliable for local environment and (4) comply with local regulation of communication. The design frame is considered and researched the following process in Fig. 1. In this process, we researched the Balsa wood material to get light weight airframe. Balsa wood is commonly used in model aircraft because of its high strength to weight ratio. Moreover it is an ideal material for light airframes because it can absorb the bending loads associated with flight without developing fatigue, and it does not corrode. And then it is a natural composite and is significantly less expensive. It can 
also be worked simple carpenter hand tools, plus homemade jigs and fixtures.

Airframe technologies include the development and optimization of structures such as wings, fuselage, stabilizers, flight control surfaces and landing gear. The main influential force in the airframe design is to reduce weight and at the same time being strong enough to withstand the forces acting on it during flight. Therefore, the structural creations for MAEU UAV must have a high strength to weight ration so as to be deemed suitable for research application.

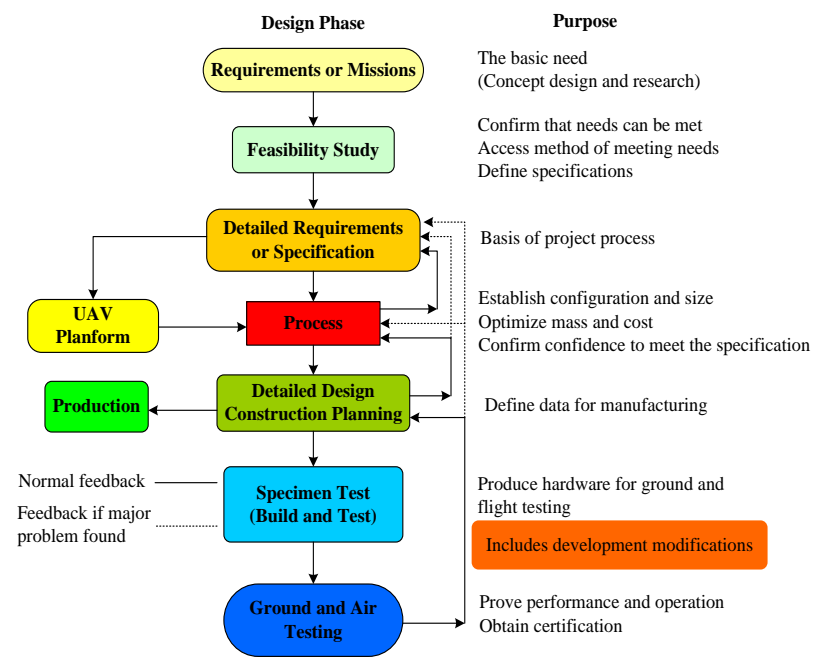

Fig. 1 Research Process Flow Chart

\section{B. Wing and Tails}

The wing and tails unit are made up of 4 main types of structural member, namely spars, stringers, ribs and skin. Because MAEU UAV are flying at subsonic speeds, the skin is relatively thin to make no contribution to bending of the wing and the bending moment is taken by spars and stringers. The wing is given an airframe design to drastically reduce the overall weight of the UAV. Two spars, which are main structural members, on located at quarter chord and the other at $3 / 4$ chord to take the transverse shear loads and span wise bending. These two spars also help to support the wing ribs that are placed chord wise along the wingspan to prevent buckling of the ribs. The wing ribs are placed at increasing intervals, from the end meeting the fuselage, to carry the panel loads.

The trailing edge structure includes the ailerons and flaps. Ribs may have large holes to reduce weight. The wooden skin may be fixed to the internal structure by bonding (gluing). Similar to the wing, the tail is designed to have an airframe structure. Due to the short span, only the number of ribs is less in tail to reduce the back weight of the vehicle than in wing. Fig. 2 and 3 are shown wing skeleton structure and tail structure.

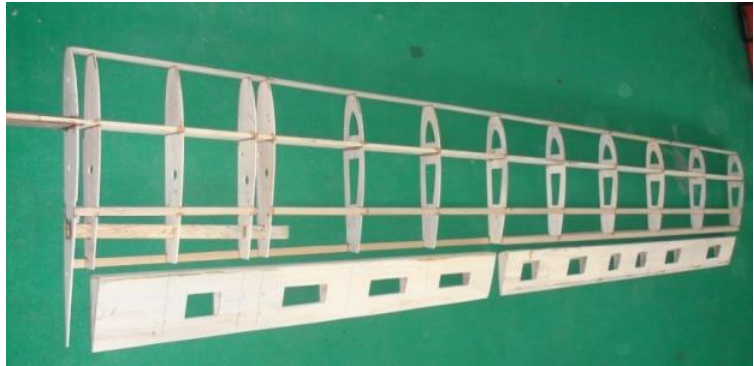

Fig. 2 Wing Skeleton Structure

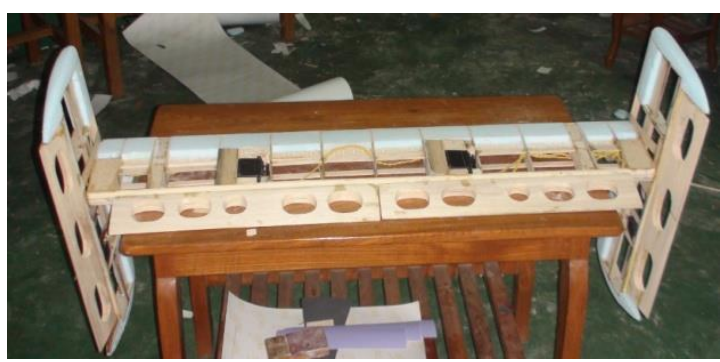

Fig. 3 Tails Structure

\section{Fuselage}

The fuselage is the central body of the aircraft since the power plant, wings, tails and landing gear are attached to it. For our research UAV, the fuselage design is made by using bulkheads, frames, longerons and stringers to get high strength and light weight. Primary bending loads are taken by longerons, which usually extend across several points of support. The longerons are supplemented by other longitudinal members (stringers). The vertical structure member, bulkheads, and frames are located at intervals to allow for concentrated loads. The strong longerons hold the bulkheads. The stringers have some rigidity but are chiefly used for giving shape and for attachment of the skin. The main advantage of this innovation is that it depends on many structural members for strength and rigidity. The engine mount is made entirely of plywood and is connected to rear fuselage.

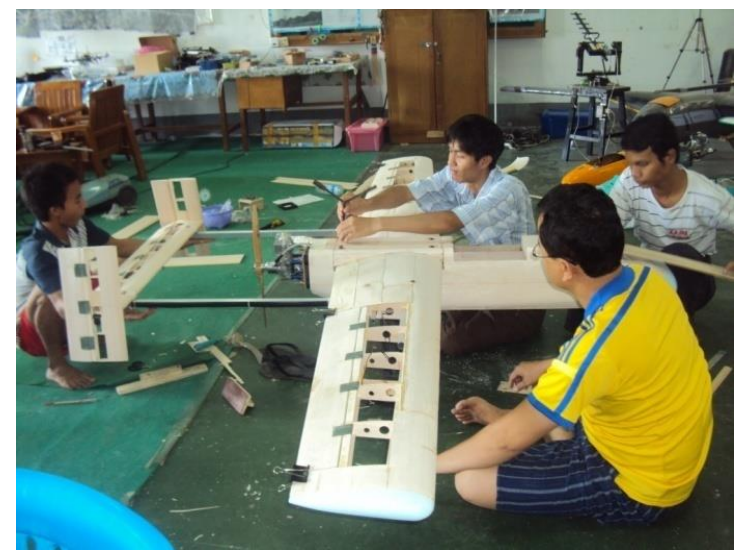

Fig. 4 Fuselage, Wing and Tail Attachment

The design specifications of our research UAV describe in Table I. The design of these airframes will use more sophisticated optimization techniques to increase both the performance and reliability of these products. 
Table I. Specifications of MAEU UAV

\begin{tabular}{|l|l|}
\hline UAV name & MAEU UAV \\
\hline Wing span & $2.7 \mathrm{~m}$ \\
\hline Overall length & $2.1 \mathrm{~m}$ \\
\hline Aircraft height & $0.6 \mathrm{~m}$ \\
\hline Takeoff weight & $13 \mathrm{~kg}$ \\
\hline Endurance & $1 \mathrm{hr}$ \\
\hline Range & $50 \mathrm{~km}$ \\
\hline Cruising speed & $30 \mathrm{~m} / \mathrm{s}$ \\
\hline Max service ceiling & $1200 \mathrm{~m}$ \\
\hline Engine power & $4 \mathrm{Hp}($ Gasoline Engine) \\
\hline Fuel capacity & 2.2 liters \\
\hline Fuel type & Octane 95 \\
\hline Payload weight & $2 \mathrm{~kg}$ \\
\hline Landing gear height & $0.245 \mathrm{~m}$ \\
\hline Takeoff / landing & Conventional runway \\
\hline Communication range & $32 \mathrm{~km}$ (900 Mhz Modem) \\
\hline Autonomous system & Fully autopilot control \\
\hline Duties & $\begin{array}{l}\text { Aerial photography \& Real time video } \\
\text { display }\end{array}$ \\
\hline
\end{tabular}

\section{AUTOPILOT RELIABILITY}

The functions of the control and stability of an UAV will depend in nature on the different aircraft configurations and the characteristics required of them. Flight control for stabilization and autonomous flight of an UAV may seem to constitute the most challenging task in the design of the system architecture.

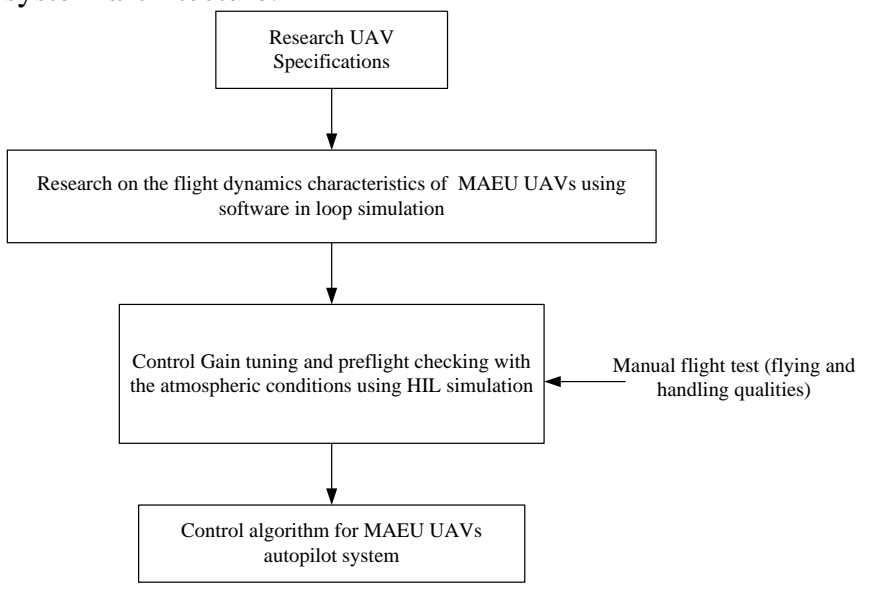

Fig. 5 Research procedure for autopilot reliability

Several significant technical challenges were overcome during the autopilot's development. The first includes a model of physical, inertial and aerodynamic platform of the MAEU UAV with atmospheric conditions. The model was constructed in flight simulation software and its simulation checks the characteristics of flight stability. Additionally, the hardware in the loop simulation (HIL) model was also constructed for initial flight test planning and controller gain tuning for autonomous system. Especially, in the flight testing process, the accuracy of control algorithms, atmospheric conditions or electronic magnetic interference leads to UAV crash. Therefore, the preflight testing and flight characteristic prediction play an important role in UAV design and its autonomous flight.

In this research, the speed command is compared with the actual airspeed as sensed as and any error between the two is obtained. Provided the power unit response is progressive, and that the correction takes place the airspeed above the minimum power speed of the UAV, the motion is stable and normally will need no damping. The actual heading of the aircraft can be measured by a magnetometer monitored attitude gyro and compared with commanded heading.

The HIL simulation, provided by X-plane technologies, was used extensively for laboratory flight simulation and preflight test. The purpose of HIL is mainly to analyze the flight characteristic of airframe including the output and input signal. We can tune the control gain parameters as well as the other system parameters. It also results in extremely precise physical properties that can be computed very quickly during level flight.

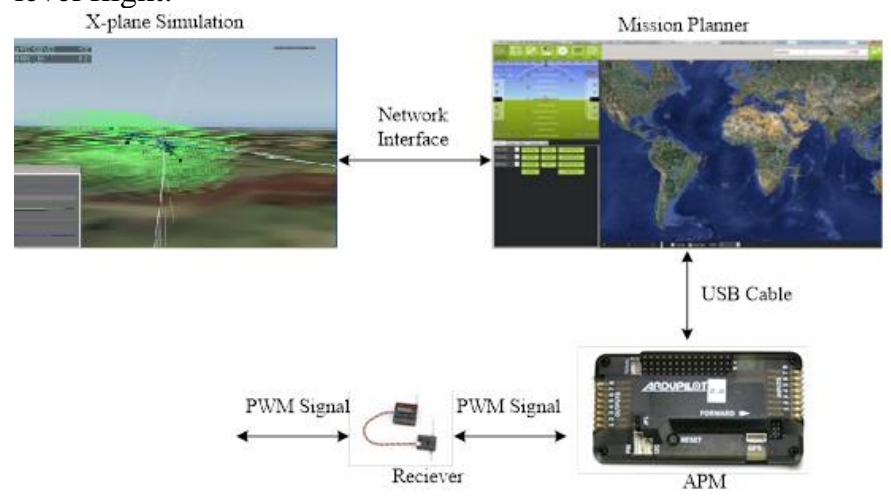

Fig. 6 HIL simulation

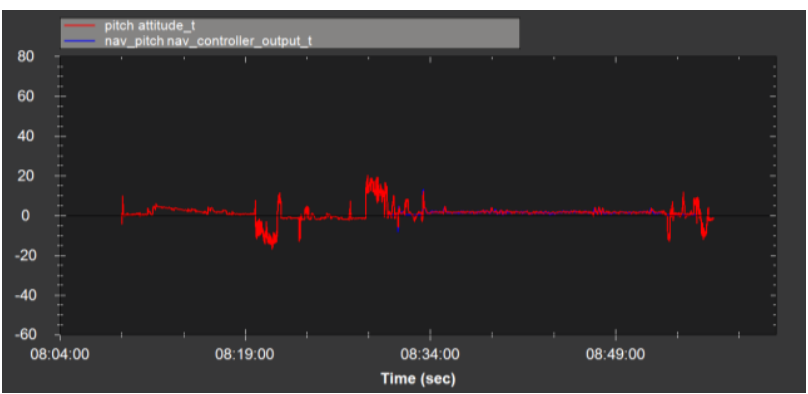

Fig. 7 MAEU UAV's pitch and navigation pitch

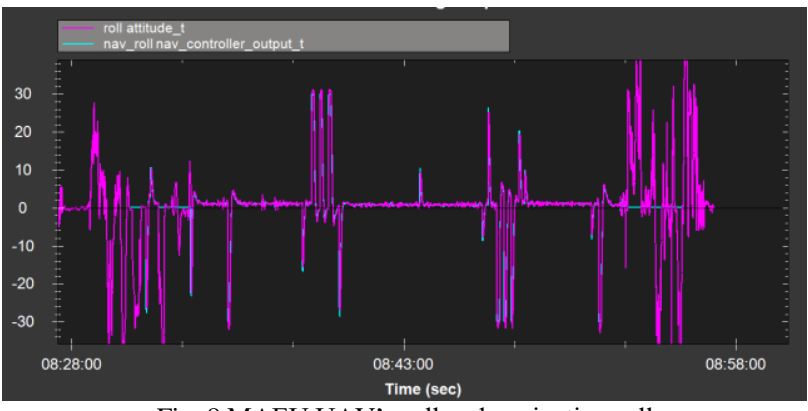

Fig. 8 MAEU UAV's roll and navigation roll

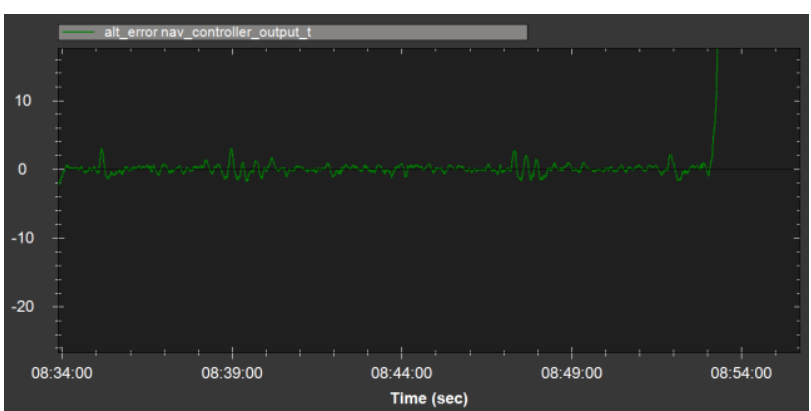

Fig. 9 MAEU UAV's altitude error 
During the simulation test, the characteristics and flying qualities of level flight were known from the experience of pilot and ground control station. The flying speed is approximately $30 \mathrm{~m} / \mathrm{s}$. The result is an aircraft with minimal overshoot, and quick error correction, at the expense of small oscillation.

\section{GROUND CONTROL STATION AND COMMUNICATION}

This research area emphasizes ground control station for attitude information, flight path showing and all kinds of error alert. In this development of Ground Control System (GCS) following the performances can do:

- Point and click waypoint entry (flight path design), using google maps

- Select mission commands from drop-down menus

- Download mission log files and analyze them

- Configure/ tuning flight control system settings for UAV airframe.

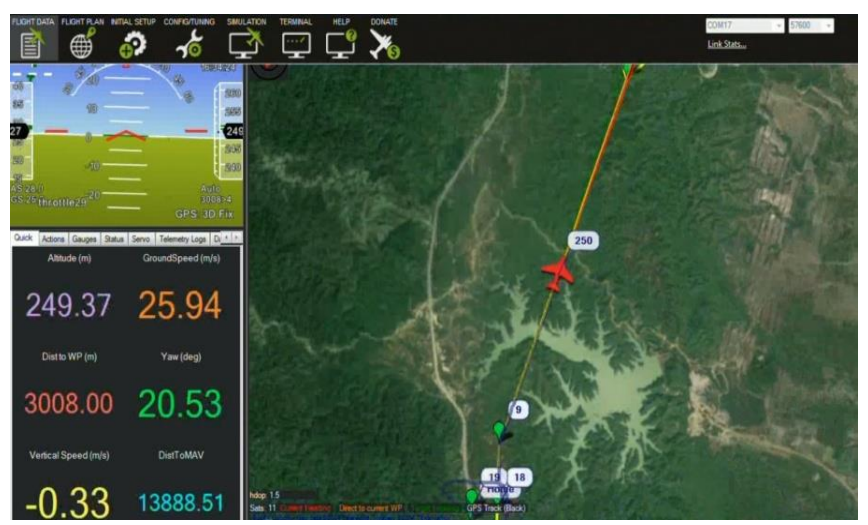

Fig. 10 MAEU UAV's ground control system

The flight control system communicates over a dedicated and separate $900 \mathrm{MHz}$ wireless link. The data link range test in 20 $\mathrm{km}$ to $60 \mathrm{~km}$ range check in $900 \mathrm{MHz}$ wireless modem between the UAV and GCS distance. The manual flight mode communicates separately over a $2.4 \mathrm{GHz}$ link.

\section{ACHIEVING RELIABILITY}

The reliability of a UAV system must be assured for the following reasons:

- If a UAV system fails whilst on a mission, then that mission has failed

- If the aircraft crushes, injuries or fatalities might be caused to the over-flown population

- Any loss of the system can result in loss of the service provided, loss of the facility and costs of repair or replacement.

Because of the above reasons, we have done the preparations in order to get safe and reliable achievements while carrying out our research program. The weather conditions in which the system will operate under 20 knots wind speed. A flight envelope have to be prepared for the aircraft, indicating its range of operating speed, acceleration limits in maneuvers and estimated accelerations imposed by air turbulence at its range of operating weight.
We have considered that defects may occur within the power plant or in other subsystems but caused by the power plant. Unless sufficient cooling is provided, a piston engine, I particular, may suffer overheating in hot conditions and fuel may become vaporized. The latter, defects caused by the engine, can result from the vibration damaging sensitive equipment or heat transfer causing overheating of the other components. So the engine is mounted on anti-vibration and heat insulating mountings. Many electronic components produce heat. Therefore they should not be too tightly packed and should be well supplied with heat sinks.

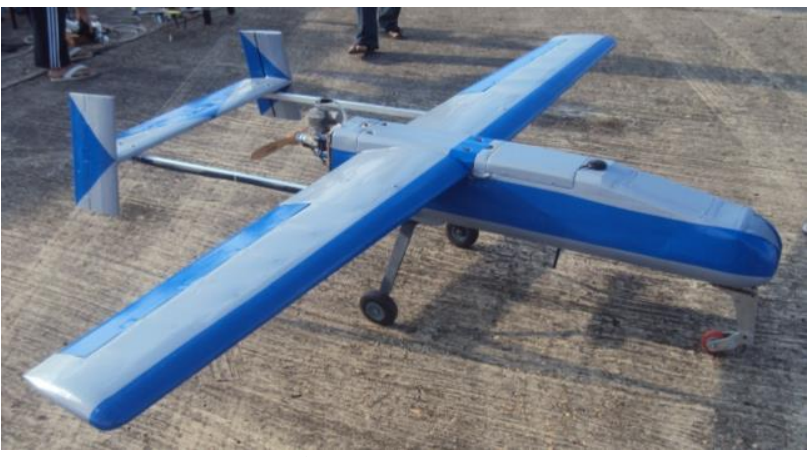

Fig. 11 MAEU UAV

\section{APPLICATION OF AERIAL IMAGING}

The MAEU UAV has succeeded in aerial imaging and design conditions meet the good performance criteria. As being reliable in design criteria, MAEU UAV has to be applied in the commercial level. It was successful of surveying for route of $500 \mathrm{KV}$ transmission line which is 120 miles (Taungoo to Phayagyi) along Yangon-Mandalay highway. This $500 \mathrm{KV}$ transmission line for Ministry of Electrical Power and Electricity (MEPE) is the biggest power line ever built in Myanmar. UAV surveying for transmission line is also the very first time and the newest technology for MEPE.

\section{A. Payload System}

The payload consists of a high resolution camera and one axis gimbal. The gimbal utilizes high torque servos with bearings and all mettle gearing creating a strong and stable platform capable of more than $1.3 \mathrm{~kg}$ of payload. The servos were modified for continuous operation to allow for additional gearing to be used to control the platforms. External potentiometers provide feedback to the servo control board allowing the position of the platforms to be directly read and any play in gearing automatically compensated for.

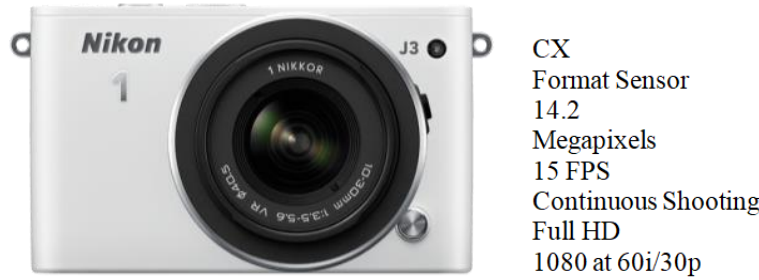

Fig. 12 MAEU UAV's payload camera 


\section{B. Flight Procedure}

MAEU UAV is able to fly with help of control points autonomously a calculated flight path at given altitude. The UAV was started to takeoff from highway and then flied round trip 20 miles with fully autopilot mode. There was 18 times flight with altitude $250 \mathrm{~m}$ and $400 \mathrm{~m}$. It was continuously monitored by ground control station (GCS) during any flight. Any flight path is a rough dangerous way which is full of hills, reservoirs, brooks of Pegu range. Although the unexpected errors come across and the crashing of UAV by means of peak of hills and encountering of cross wind effect, our UAV overcame these difficulties.

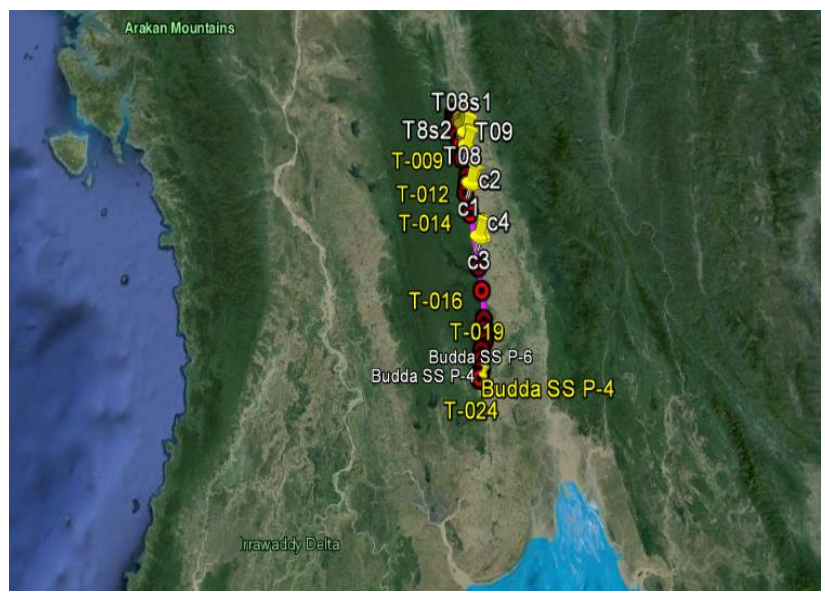

Fig. $13500 \mathrm{KV}$ transmission line route

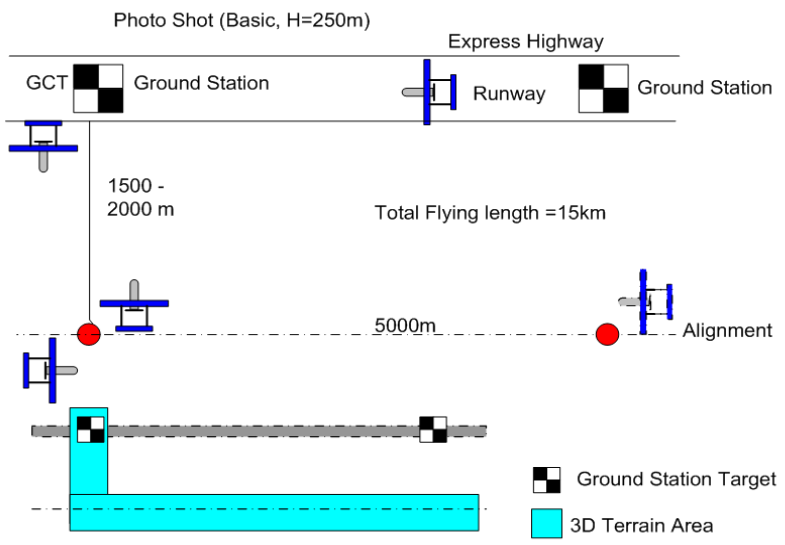

Fig. 14 MAEU UAV's flying process

In this stage, firstly the requirements of the mission need to be analyzed and defined in order to determine flight parameters as well as the area of interest in Fig. 13. Second, an initial set of flight plans, in the form of Google Earth KML files and waypoints files, are created. Third, a UAV team verifies the flight plan before UAV is flown by performing a preflight survey. The desired image scale and used camera focal length are generally fixed in order to derive the mission flying height. The image network quality is strongly influenced by the topology of the performed flight in Fig. 14.

Fig. 15 describes the flight path for one sector. For ground survey work, the images need to be geo-corrected. Ground control points are usually markers placed on the ground with Global Navigation Satellite System instruments in Fig. 16.

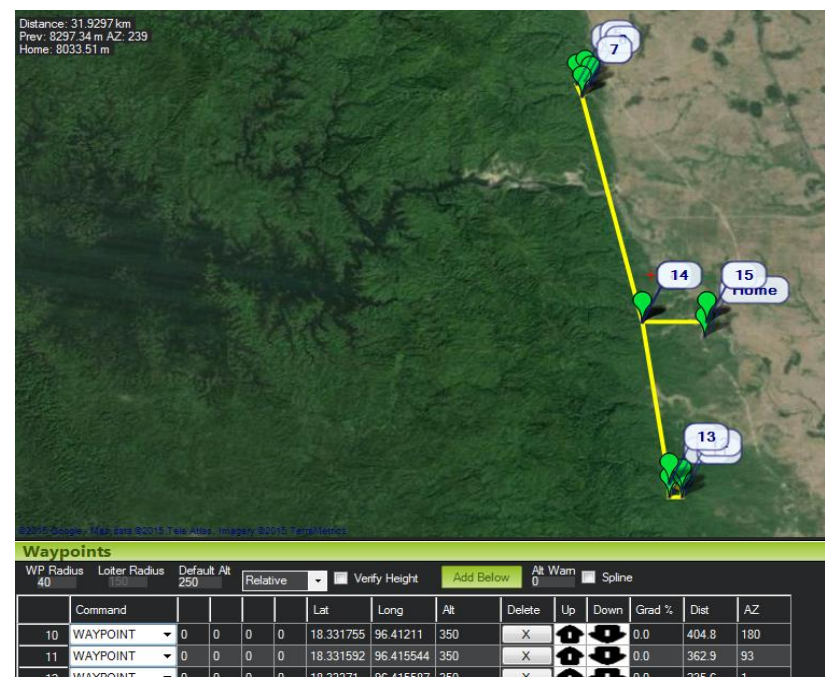

Fig. 15 MAEU UAV's flight planning

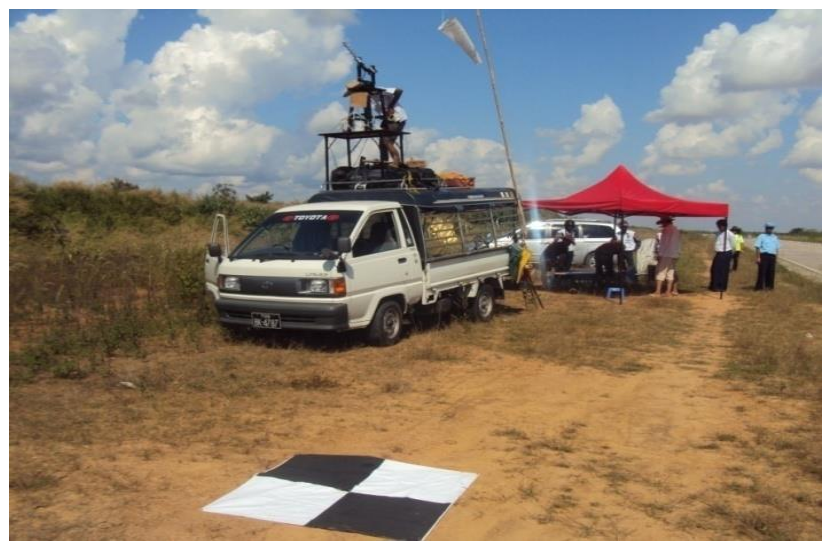

Fig. 16 Ground control point

The results indicate that with low cost UAV and photogrammetric techniques, it is possible to obatin high quality products. The output map has 3D, plan and longitudinal sections detailed in Fig. 20. Regarding the georeferencing accuracy, a comparison was made between using only onboard GNSS and including external GCPs for image orientation. This is due to the use of a consumer grade GNSS instrument.

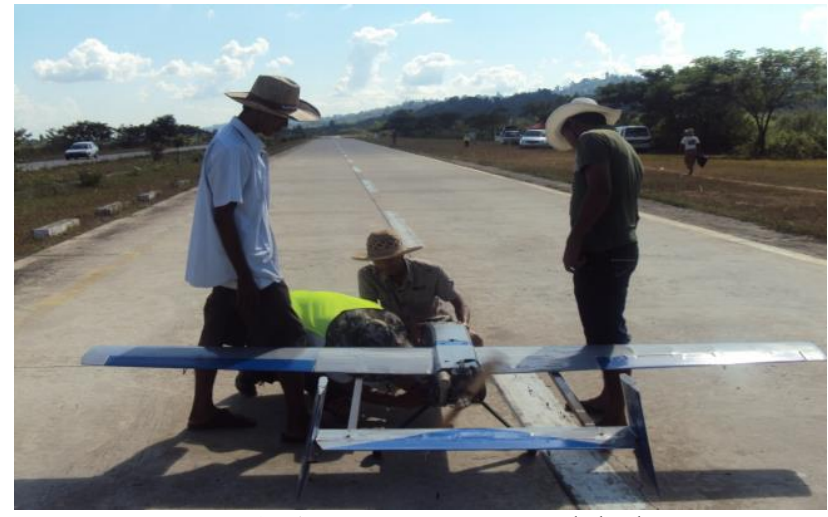

Fig. 17 MAEU UAV’s ground check 


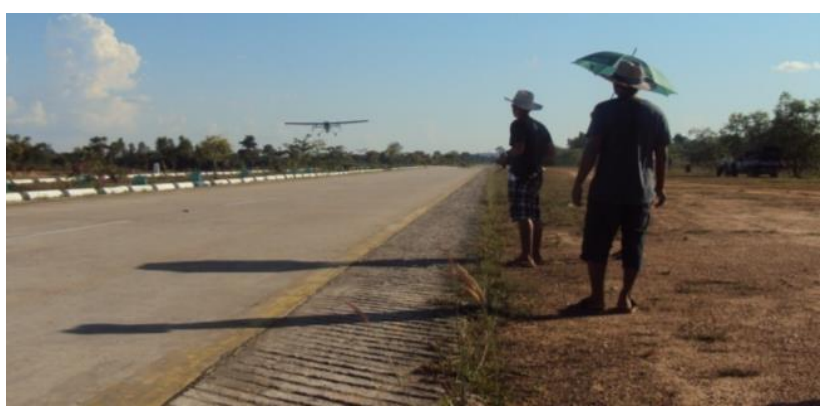

Fig. 18 MAEU UAV's takeoff performance

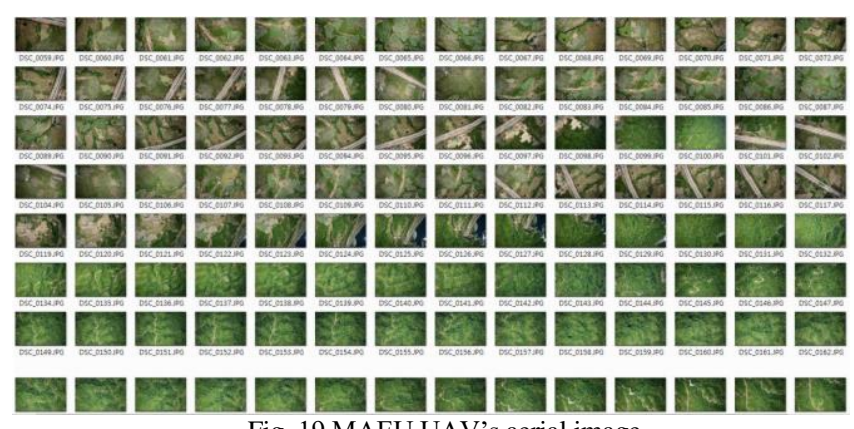

Fig. 19 MAEU UAV's aerial image
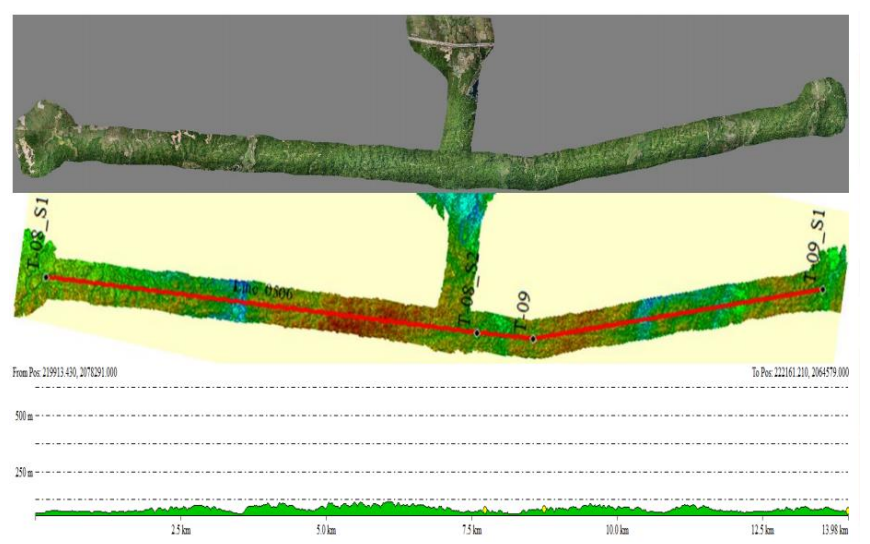

Fig. 20 MAEU UAV's output map

Finally the out coming of aerial photos from MAEU UAV can be used as survey mapping for transmission line. By using UAV for surveying $500 \mathrm{KV}$ transmission line provides substantial benefits for our country. It will reduce cost, labour and time consuming. UAV aerial surveys offer an effective and more precision technique to traditional topographic surveys, sattelite imagery, and ground reconnaissance. In cases where manual survey techniques are potentially unsafe or traditional topographic surveys are uneconomical. Moreover the total cost of MAEU UAV is about 15000usd including airframe, engine and accessories, autopilot control system, avionics equipments and ground control system. It is much more cost effective than foreign UAVs up to $60 \%$ cheaper. The total distance is 240 miles and the total flight duration has 6 hours and 30 minutes. The success of UAV aerial photographing for $500 \mathrm{KV}$ line is a corner stone of Myanmar.

\section{CONCLUSION}

This project has successfully achieved it objective of design, integrate and test onboard for MAEU UAV to measure, store and transmit video and data to a ground control station. HIL simulator have been successfully build to test the accuracy and performance of autopilot system, and to reduce the unnecessary risks and disturbances. This research can identify technology developments that would improve the performance and reliability of low cost UAV and recommended areas of research in structures and aeronautical concepts. It is demonstrated that UAV together with the digital camera are capable of acquiring aerial photograph successfully for large scale mapping in a short amount of time. The digital terrain model data from UAV images processed is used to evaluate the geographic features where it must follow the design policy parameters in order to help control the design of transmission tower.

\section{ACKNOWLEDGMENT}

The author wishes to express deepest gratitude to all persons who helped directly and indirectly from the research level towards the application one.

\section{REFERENCES}

[1] Ralph D. Kimberlin, "Flight Testing of Fixed-Wing Aircraft", Education Series,AIAA,(2003).

[2] Thomas C.Croke, "Design of Aircraft", Person Education,(2003).

[3] Durham, W.C, "Aircraft Dynamics and Control, Class notes", Aerospace and Ocean Engineering Department, Virginia Polytechnic Institute and State University,(2002).

[4] Hsiao, F.B. and Lee, M.T, "The Development of Unmanned Aerial Vehicle in RMRL/NCKU", $4^{\text {th }}$ Pacific International Conference on Aerospace Science and Technology, Kaohsiung, Taiwan, May(2001).

[5] Minor, John, Thurling, Andrew, J.,Ohmit and Eric, "VISTA-A $21^{\text {st }}$ Century UAV Testbed", United States Air Force Test Pilot School website, 10May(2001).

[6] Raymer, Daniel P, “Aircraft Design: A conceptual Approach", $3^{\text {rd }}$ Ed, AIAA Education Series,(1999).

[7] Branes, G., et al., "Drones for peace: Part 1 of 2 design and testing of a UAV based cadastral surveying and mapping methodology in Albania", World bank conference on land and poverty, Washington DC, USA, March (2014).

[8] Colomina, I, and Molina, P., "Unmanned aerial systems for photogrammetry and remote sensing: a review" , ISPRS Journal of photogrammetry and remote sensing, 92,79-97, Feb (2014). 